\title{
Oral cancer histopathological subtypes in association with risk factors: a 5-year retrospective study
}

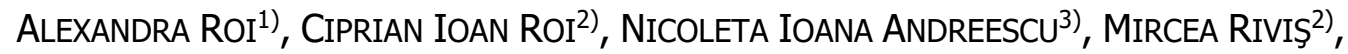

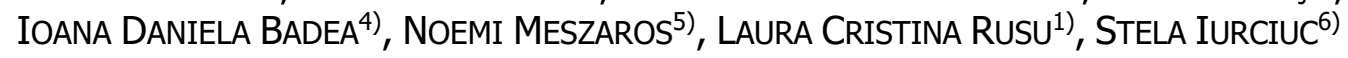 \\ 1) Department of Oral Pathology, Multidisciplinary Center for Research, Evaluation, Diagnosis and Therapies in Oral Medicine, \\ Faculty of Dental Medicine, Victor Babeş University of Medicine and Pharmacy, Timişoara, Romania \\ 2) Department of Anesthesiology and Oral Surgery, Multidisciplinary Center for Research, Evaluation, Diagnosis and Therapies \\ in Oral Medicine, Faculty of Dental Medicine, Victor Babeş University of Medicine and Pharmacy, Timişoara, Romania \\ 3) Department of Microscopic Morphology - Genetics, Center of Genomic Medicine, Multidisciplinary Center for Research, \\ Evaluation, Diagnosis and Therapies in Oral Medicine, Victor Babeş University of Medicine and Pharmacy, Timişoara, Romania \\ 4) PhD Student, Multidisciplinary Center for Research, Evaluation, Diagnosis and Therapies in Oral Medicine, \\ Victor Babeş University of Medicine and Pharmacy, Timişoara, Romania \\ 5) Department of Life Sciences, Faculty of Medicine, Vasile Goldis Western University of Arad, Romania \\ 6) Discipline of Ambulatory Internal Medicine, Cardiovascular Prevention and Rehabilitation, Department of Cardiology, \\ Multidisciplinary Center for Research, Evaluation, Diagnosis and Therapies in Oral Medicine, Faculty of Medicine, \\ Victor Babeş University of Medicine and Pharmacy, Timişoara, Romania
}

\begin{abstract}
Background: Oral cancer is a worldwide public health problem, being the sixth most common neoplasm. The high mortality rate of this type of cancer is due to a delayed diagnosis, a fast evolution and metastasis, no primary symptomatology, the multitude of risk factors and the lack of awareness among the population concerning oral malignancy. Aim: The aim of this 5-year retrospective study was to evaluate the incidence of oral cancer patients in the Clinic of Maxillo-Facial Surgery, Emergency County Hospital, Timişoara, Romania and quantify the histopathological (HP) subtypes, localization, age, gender, tumor staging and differentiation, positive loco-regional lymph nodes and risk factors. Patients, Materials and Methods: A number of 129 patients diagnosed with oral cancer were included in the study and their medical records were analyzed. A statistical analysis was performed that included the variables gender, age, tumor staging, differentiation grade, HP subtype, lymph nodes, localization, and risk factors. Results: Our results outlined a high prevalence of oral cancer among males (65.9\%), squamous cell carcinoma (SCC) being the most common HP subtype. Tumor staging revealed the fact that the majority of were T3 and T4 tumors with dissemination in the loco-regional lymph nodes. In $52 \%$ of the cases, tobacco was identified as a risk factor, and the association of tobacco and alcohol was present in $28.3 \%$ of the cases. Conclusions: The early diagnosis is crucial for the improvement of oral cancer survival rate. The oral cavity is permanently exposed to carcinogenic substances that associated with other risk factors have an influence upon the incidence of oral malignancies.
\end{abstract}

Keywords: oral cancer, risk factors, histopathological subtypes, early diagnosis, oral cancer screening

\section{a Introduction}

Oral cancer is considered a major global public health problem [1], with a concerning increase during the past years besides the preventive measures [2]. According to the World Health Organization (WHO), cancer is an important death cause worldwide, and approximately 3\% of all cancers are represented by oral cancer [3]. Currently, oral cancer is ranking the sixth place regarding its incidence among all the malignancies [4].

Although at the beginning there was an association between the recurrence in undeveloped countries, the present studies show an extensive spreading in developing countries as well [5]. Oral cancer epidemiology aims to outline the incidence in various populations, geographic areas, socioeconomical status and associated risk factors. The outcome of the epidemiological studies is often discussed, as the anatomical localizations can be differently influenced, and the actual disease incidence can be difficult to assess. The purpose of the International Classification of Diseases for Oncology (ICD-O) was to classify based on the localization into oral cavity cancer that includes the lip, gums, dorsal surface of the tongue, buccal mucosa, hard palate mucosa, soft palate mucosa and the floor of the mouth, while the oropharyngeal cancer includes the base of the tongue, tonsils, lateral wall of oropharynx and the pharynx [6].

One of the major oral cancer risk factors is represented by tobacco, and the International Agency for Research on Cancer (IARC) classifies it as being a group 1 carcinogenic substance for the oral cavity [7]. Gandini et al. [8] performed a meta-analysis and outlined the associated relative risk between tobacco smokers compared to the non-smokers as having a $6.76 \%$ higher risk for developing oral squamous cell carcinoma (SCC). Most of the studies from Europe, United States and Asia have

This is an open-access article distributed under the terms of a Creative Commons Attribution-NonCommercial-ShareAlike 4.0 International Public License, which permits unrestricted use, adaptation, distribution and reproduction in any medium, non-commercially, provided the new creations are licensed under identical terms as the original work and the original work is properly cited. 
indicated an increased oral cancer risk in association with alcohol consumption, as being an independent risk factor whose influence depends by the dose and the response of the oral cavity mucosa $[9,10]$. Although, the exact carcinogenic mechanism is not entirely known, the ethanol is metabolized by the microflora and epithelial cells and transformed into acetaldehyde, which represents the carcinogenic substance. An existing polymorphism in the genes that metabolize alcohol (aldehyde dehydrogenase 1 $[A L D H 1]$ gene, aldehyde dehydrogenase $2[A L D H 2]$ gene, alcohol dehydrogenase $1 \mathrm{~B}[A D H 1 B]$ gene and alcohol dehydrogenase $1 \mathrm{C}[A D H 1 C]$ gene) has been associated with the high incidence of oral cancer [11, 12]. Epidemiological, molecular, clinic and pathological studies have reported human papillomavirus (HPV) as a major risk factor for the head and neck cancer. The high-risk HPV-16 was identified (approximately $90-95 \%$ of the cases) in HPV-positive patients that were diagnosed with oropharyngeal cancer, and in case of the oral mucosa cancer, the HPV subtypes were more variable [13].

Recent research shows an important impact of the oral microbiome upon the development of oral cancer. The results demonstrate a difference encountered in the oral microbiome of healthy patients and patients diagnosed with oral cancer [14]. Although the change of the oral microbiome is a certain fact, it cannot be stated if it is directly involved in the carcinogenesis process, or it is a consequence and an adaptation to the microenvironment determined by cancer [14]. There are several characteristics of the oral microbiome that could explain the involvement in the carcinogenesis, such as the production of carcinogens, the induction of a chronic state of inflammation, the metabolism of procarcinogens and the alteration of the deoxyribonucleic acid (DNA) through the production of bacterial toxins $[14,15]$. Other variable risk factors that have been associated with the incidence of oral cancer are the immune status $[16,17]$, the dietary habits and various mineral/vitamin deficiencies $[18,19]$, hereditary conditions [20], environmental pollutants [21] and occupational exposures [22].

\section{Aim}

The aim of our retrospective study was to evaluate and quantify the incidence of oral cancer, its histopathological (HP) subtypes and the affected anatomical sites of the oral cavity in relation to various patient-related variables and risk factors.

\section{Patients, Materials and Methods}

\section{Study design}

In this observational, retrospective, and quantitative study, we reviewed the medical records of patients that were diagnosed with oral cancer and treated in the Clinic of Maxillo-Facial Surgery, Emergency County Hospital, Timişoara, Romania, between January 2015-December 2020. The inclusion criteria were as follows: the confirmed diagnosis of oral cancer based on a previous biopsy and HP examination, both genders, age over 18 years. The exclusion criteria were any previous chemotherapy or radiotherapy treatments in the head and neck area, oral cancer relapse. A written consent of the patients was obtained at the moment of the hospitalization (based on the ethical principles enounced in the Declaration of Helsinki) and the Ethics Committee approval was obtained.

\section{Description of variables}

The socio-demographic information such as gender, average age, the diagnosis, risk factors, the tumor histological type and differentiation grade, the localization in the oral cavity, the existence of lymph node metastasis and the stage of the tumor were the variables included in our study. The anatomical sites of the oral mucosa that were involved were classified based on the $W H O$ criteria (lip, gingiva, anterior third of the tongue, hard palate, mouth floor and other parts). The encountered histological types were divided into SCC, basal cell carcinoma (BCC), adenocarcinoma, adenoid cystic carcinoma, mucoepidermoid carcinoma. Also, the tumor staging was according to the $W H O$ directives: $\mathrm{T}$ representing the tumor size, $\mathrm{N}$ representing the lymph node involvement, and $\mathrm{M}$ the existence of metastasis. The tumor staging was noted as following: stage I (T1, N0, M0) stage II (T2, N0, M0), stage III (T3, N0, M0/T1 to T3, N1, M0), stage IVA (T4a, N0 or N1, M0), stage IVB (any T, N3, M0/T4b, any N, M0), stage IVC (any T, any N, M1). The differentiation grade has an important prognostic value, being a result of the histological alterations. There are four degrees of differentiation, being described as G1 (well differentiated, the cells look more like normal tissue and are well differentiated), G2 (the cells are only moderately differentiated), G3 (poorly differentiated) and G4 (undifferentiated).

\section{The microscopic analysis of the tumor sample}

The tumor samples were inserted into $10 \%$ neutral buffered formalin for 48 hours. The amount of formalin that was used was 20 times higher than the volume of the tissue sample. The fixation served in order to preserve the cellular and tissue substrates that are kept in order to establish the diagnosis of the lesion. Washing was a mandatory step after fixing, allowing the formalin to be removed. After this step, the tissue was embedded in paraffin, which was performed according to the usual histological method. For the inclusion stage, standardized Thermo Shandon inclusion was used. Tissue processing was performed by dehydration with alcohol in increasing concentrations $(70 \%, 80 \%, 90 \%, 96 \%, 100 \%)$, clarification with benzene. The volume of the paraffin bath was 10 times higher than the volume of the piece. Obtaining the blocks was possible by using cassettes and the sectioning was performed using the microtome. From each block, 10 sections with a thickness of $3 \mu \mathrm{m}$ each were made and were glued with Mayer's albumin on degreased histological slides and stretched in a hot aqueous medium. Drying is obtained at $37^{\circ} \mathrm{C}$ for $20-30$ minutes. Deparaffinizing is performed by a benzene bath on a thermostat at $57^{\circ} \mathrm{C}$ for 30 minutes, followed by two benzene baths at room temperature, 10 minutes each. Hydration was achieved by passing the dewaxed sections through successive baths of alcohols in decreasing concentrations $(100 \%, 96 \%, 80 \%, 70 \%), 10$ minutes each bath, followed by a bath of distilled water for 10 minutes. The stages of morphological staining, performed 
automatically, are the following: deparaffinizing, hydration; Harris Hematoxylin staining 30 seconds; wash with tap water for five minutes; washing with distilled water for five minutes; Eosin staining two minutes; washing with distilled water five minutes; dehydration in two baths of absolute ethyl alcohol (five minutes each); air drying and clarification in benzene 20 minutes. Afterwards, the microscopic analysis of the sections was performed.

Based on the collected data from the medical records (personal information, anamnesis, associated risk factors and HP results), a statistical analysis was performed in order to assess the existing correlations between the targeted variables for further conclusions.

\section{Results}

The total number of patients included in the study that were diagnosed with oral cancer and treated in the Clinic of Maxillo-Facial Surgery, Emergency County Hospital, Timişoara, between January 2015-December 2020 was 129. The average age (including both genders) was 63.9 years, and the gender distribution was the following: 85 (65.9\%) males and 44 (34.1\%) females (Table 1).

The male average age was 61.8 years, meanwhile the female average age was 66 years. The minimum age of the patients was 38 years, and the maximum age was 90 years. The patients were divided into seven groups based on different age intervals and the results showed the fact that the patients from group IV (61-70 years) represented $35.6 \%$ of the cases, followed by group V (71-80 years) with $26.3 \%$, group III (51-60 years) with $23.2 \%$, group II (41-50 years) with $10 \%$, group VI ( $>81$ years) with $3.1 \%$ and group I (31-40 years) with $1.5 \%$ (Table 2).
As for the localization of the malignant lesions, the affected anatomical sites were the oral floor mucosa (right/left/bilateral), lip (upper/lower), tongue mucosa, the mandibular alveolar mucosa, the maxillary alveolar mucosa, retromolar triangle, jugal mucosa, hard palate, soft palate, the tuberosity, intermaxillary commissure. Also, the involvement of the lymph nodes was divided into submental, submandibular (left/right/bilateral), laterocervical (right/left/bilateral), both submental and submandibular (right/left) and both submandibular and latero-cervical (right/left) (Table 3 ).

Table 1 - Gender and average age distribution

\begin{tabular}{|c|c|c|c|c|}
\hline Variables & & & $\begin{array}{c}\text { No. of } \\
\text { patients }\end{array}$ & Percentage \\
\hline Total cases & & & 129 & $100 \%$ \\
\hline \multirow{2}{*}{ Gender } & Males & & 85 & $65.9 \%$ \\
\hline & Females & & 44 & $34.1 \%$ \\
\hline \multirow{3}{*}{ Age } & $\begin{array}{c}\text { Males + females } \\
\text { (average) }\end{array}$ & $\begin{array}{c}63.9 \\
\text { years }\end{array}$ & & \\
\hline & $\begin{array}{c}\text { Males } \\
\text { (average) }\end{array}$ & $\begin{array}{c}61.8 \\
\text { years }\end{array}$ & & \\
\hline & $\begin{array}{l}\text { Females } \\
\text { (average) }\end{array}$ & $\begin{array}{c}66 \\
\text { years }\end{array}$ & & \\
\hline
\end{tabular}

Table 2 - Incidence of oral cancer in different age groups

\begin{tabular}{ccc}
\hline Age group (years) & No. of patients & Percentage \\
\hline Group I (31-40) & 2 & $1.55 \%$ \\
\hline Group II (41-50) & 13 & $10 \%$ \\
\hline Group III (51-60) & 30 & $23.25 \%$ \\
\hline Group IV (61-70) & 46 & $35.65 \%$ \\
\hline Group V (71-80) & 34 & $26.35 \%$ \\
\hline Group VI (>81) & 4 & $3.1 \%$ \\
\hline
\end{tabular}

Table 3 - Statistical analysis regarding the localization, existing lymph nodes, histopathological subtype, $T$ stage and involved risk factors

\begin{tabular}{|c|c|c|c|c|}
\hline Variables & & & No. of patients & Percentage \\
\hline Total cases & & & 129 & $100 \%$ \\
\hline \multirow{22}{*}{ Localization } & \multirow{3}{*}{ Oral floor } & Right & 11 & $8.5 \%$ \\
\hline & & Left & 18 & $14 \%$ \\
\hline & & Bilateral & 6 & $4.6 \%$ \\
\hline & \multirow{2}{*}{ Lip } & Upper & 5 & $3.9 \%$ \\
\hline & & Lower & 14 & $10.8 \%$ \\
\hline & \multirow{5}{*}{ Tongue } & Right border & 8 & $6.2 \%$ \\
\hline & & Left border & 5 & $3.9 \%$ \\
\hline & & Anterior third & 5 & $3.9 \%$ \\
\hline & & Middle third & 8 & $6.2 \%$ \\
\hline & & Base & 5 & $4.6 \%$ \\
\hline & \multirow{2}{*}{ Mandibular alveolar mucosa } & Right & 10 & $7.7 \%$ \\
\hline & & Left & 6 & $4.6 \%$ \\
\hline & \multirow{2}{*}{ Maxillary alveolar mucosa } & Right & 5 & $3.9 \%$ \\
\hline & & Left & 2 & $2.3 \%$ \\
\hline & Retromolar triangle & Right & 1 & $0.7 \%$ \\
\hline & \multirow{2}{*}{ Jugal mucosa } & Right & 1 & $0.7 \%$ \\
\hline & & Left & 4 & $3.1 \%$ \\
\hline & Hard palate & Right & 3 & $2.3 \%$ \\
\hline & Soft palate & & 5 & $3.9 \%$ \\
\hline & Tuberosity & Left & 1 & $0.7 \%$ \\
\hline & \multirow{2}{*}{ Intermaxillary commissure } & Right & 2 & $1.5 \%$ \\
\hline & & Left & 2 & $1.5 \%$ \\
\hline
\end{tabular}




\begin{tabular}{|c|c|c|c|c|}
\hline Variables & & & No. of patients & Percentage \\
\hline \multirow{12}{*}{ Nodes } & & & 56 & $43 \%$ \\
\hline & Submental & & 2 & $3.6 \%$ \\
\hline & \multirow{3}{*}{ Submandibular } & Right & 7 & $12.5 \%$ \\
\hline & & Left & 6 & $10.7 \%$ \\
\hline & & Bilateral & 1 & $1.7 \%$ \\
\hline & \multirow{3}{*}{ Latero-cervical } & Right & 9 & $16 \%$ \\
\hline & & Left & 7 & $12.5 \%$ \\
\hline & & Bilateral & 3 & $5.3 \%$ \\
\hline & \multirow{2}{*}{ Both submental and submandibular } & Right & 1 & $1.7 \%$ \\
\hline & & Left & 3 & $5.3 \%$ \\
\hline & \multirow{2}{*}{ Both submandibular and latero-cervical } & Right & 4 & $7.1 \%$ \\
\hline & & Left & 16 & $28.5 \%$ \\
\hline \multirow{5}{*}{ Histopathological subtype } & Squamous cell carcinoma & & 118 & $91.5 \%$ \\
\hline & Basal cell carcinoma & & 2 & $1.5 \%$ \\
\hline & Adenocarcinoma & & 4 & $3.1 \%$ \\
\hline & Adenoid cystic carcinoma & & 2 & $1.5 \%$ \\
\hline & Mucoepidermoid carcinoma & & 3 & $2.4 \%$ \\
\hline \multirow{4}{*}{ T stage } & T1 & & 10 & $7.8 \%$ \\
\hline & $\mathrm{T} 2$ & & 31 & $24 \%$ \\
\hline & T3 & & 53 & $41 \%$ \\
\hline & $\mathrm{T} 4$ & & 35 & $27 \%$ \\
\hline \multirow{4}{*}{ Differentiation grade } & G1 (well differentiated) & & 20 & $25.8 \%$ \\
\hline & G2 (moderate differentiated) & & 39 & $50.3 \%$ \\
\hline & G3 (poorly differentiated) & & 42 & $54.1 \%$ \\
\hline & G4 (undifferentiated) & & 28 & $36.1 \%$ \\
\hline \multirow{3}{*}{ Risk factors } & Tobacco & & 67 & $52 \%$ \\
\hline & Alcohol & & 31 & $24 \%$ \\
\hline & Tobacco + alcohol & & 22 & $28.3 \%$ \\
\hline
\end{tabular}

The lower lip was the most frequent affected anatomical site ( $n=14$ patients, $10.8 \%$ ) (Figure 1), followed by the left oral floor mucosa ( $n=18$ patients, $14 \%$ ), the right oral floor mucosa ( $n=11$ patients, $8.5 \%$ ), the right border of the tongue $(n=8,6.2 \%)$ (Figure 2$)$, the middle third of the tongue $(n=8,6.2 \%)$, the base of the tongue $(n=6,4.6 \%)$, bilateral oral floor mucosa $(n=6,4.6 \%)$, left mandibular alveolar mucosa $(n=6,4.6 \%)$, the upper lip $(n=5,3.9 \%)$, the left border of the tongue $(n=5,3.9 \%)$, the anterior third of the tongue $(n=5,3.9 \%)$, right maxillary alveolar mucosa $(n=5,3.9 \%)$, soft palate $(n=5,3.9 \%)$ (Figure 3$)$, left jugal mucosa $(n=4,3.1 \%)$, left maxillary alveolar mucosa $(n=3,2.3 \%)$, right hard palate $(n=3,2.3 \%)$ right intermaxillary commissure $(n=2,1.5 \%)$, left intermaxillary commissure $(n=2,1.5 \%)$, retromolar triangle $(n=1,0.7 \%)$, right jugal mucosa $(n=1,0.7 \%)$ and left tuberosity $(n=1$, $0.7 \%$ ) (Table 3).

Positive lymph nodes were encountered in $56(43 \%)$ patients out of 129 patients included in our study. Both left submandibular and latero-cervical lymph nodes were more frequently involved $(n=16,28.5 \%)$, right laterocervical $(n=9,16 \%)$, right submandibular $(n=7,12.5 \%)$, left latero-cervical $(n=7,12.5 \%)$, left submandibular $(n=6$, $10.7 \%$ ), both right submandibular and latero-cervical $(n=4,7.1 \%)$, bilateral latero-cervical implication $(n=3$, $5.3 \%)$, left side both submental and latero-cervical $(n=3$, $5.3 \%)$, submental lymph nodes $(n=2,3.6 \%)$, bilateral latero-cervical lymph nodes $(n=1,1.7 \%)$, right side both submental and latero-cervical lymph nodes $(n=1,1.7 \%)$. The tumor $(\mathrm{T})$ staging revealed the fact that $10(7.8 \%)$ patients had T1, 31 (24\%) patients had T2, $53(41 \%)$ patients had T3, and 35 (27\%) patients had T4 (Table 3).
Oral cancer tumor grading is an important variable in assessing the aggressiveness of the malignant cells, with an important impact upon the future therapeutic decision. A high degree of differentiation is associated with a low risk of metastasis, compared to a poorly differentiated tumor that usually is characterized by an aggressive evolution. In our study, G1 tumors represented $25.8 \%$ $(n=20)$, G2 50.3\% $(n=39), \mathrm{G} 354.1 \%(n=42)$, and G4 $36.1 \%(n=28)$ (Table 2).

The identified HP subtypes showed a high prevalence of the oral SCC $91.5 \%(n=118)$ fact that is according to the literature, adenocarcinoma $3.1 \%(n=4)$, mucoepidermoid carcinoma $2.4 \%(n=3)$, BCC $1.5 \%(n=2)$, and adenoid cystic carcinoma $1.5 \%(n=2)$ (Table 3$)$.

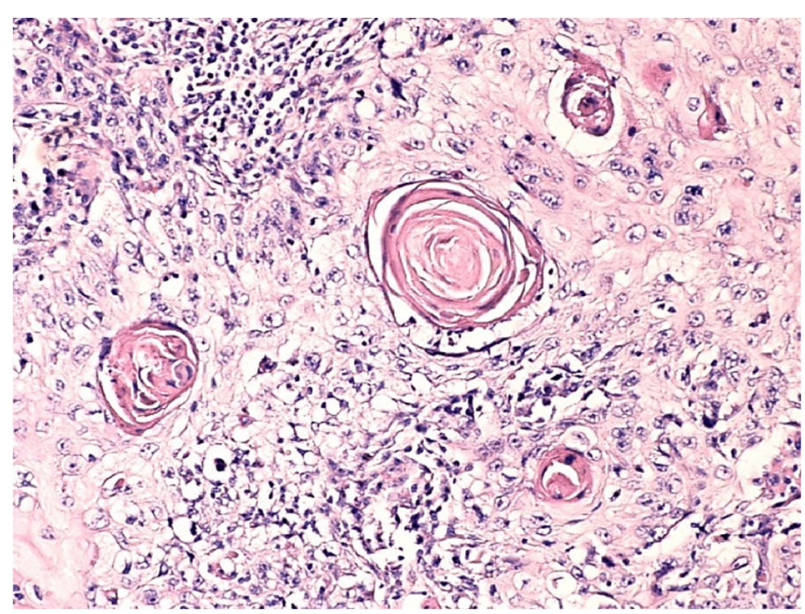

Figure 1 - Lip squamous cell carcinoma, T1NOMO, G1 (well differentiated). HE staining, $\times 200$. 


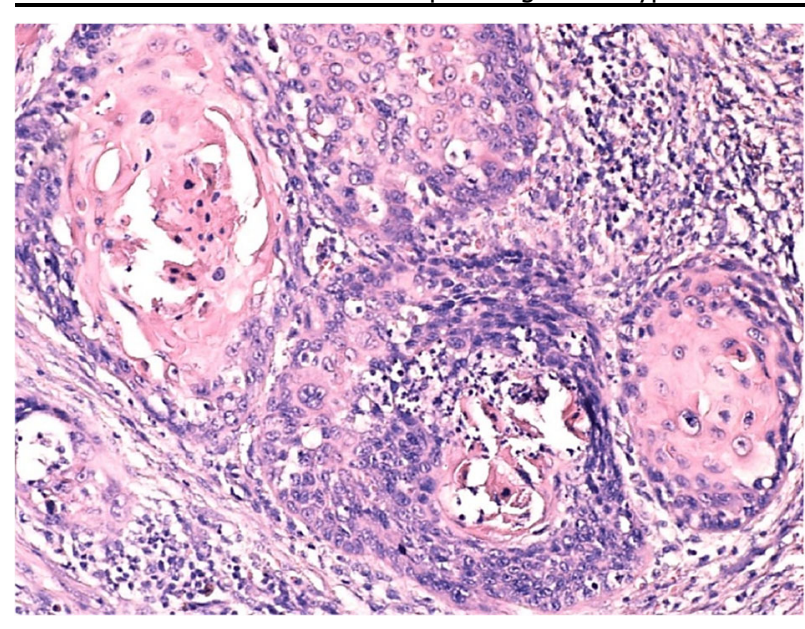

Figure 2 - Epidermoid carcinoma of the lingual mucosa, T2NOMO, G2 (moderate differentiated). HE staining, $\times 200$.

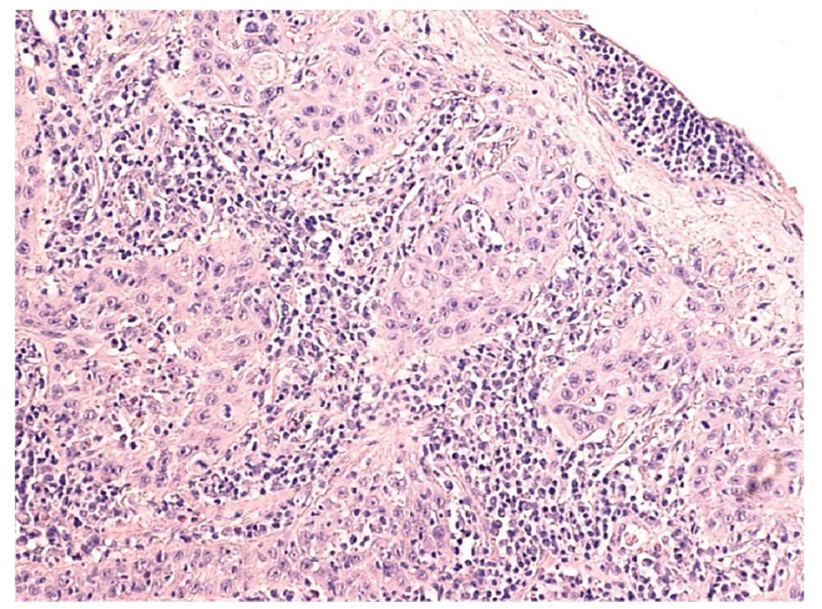

Figure 3 - Oral squamous cell carcinoma, T1N3M0, G3 (poorly differentiated). HE staining, $\times 200$.

The identified risk factors were tobacco, alcohol and the combination of tobacco and alcohol. Tobacco was associated in $52 \%$ of the patients $(n=67)$, alcohol in $24 \%$ $(n=31)$ and both combined in $28.3 \%(n=2)$ (Table 3$)$.

The correlation of the HP subtypes and the localization of the primary tumor revealed the fact that oral SCC was the most prevalent $(91.4 \%$ of the cases, $n=118)$, followed by adenocarcinoma $(3.1 \%, n=4)$, mucoepidermoid carcinoma $(2.32 \%, n=3)$, BCC $(1.55 \%, n=2)$, and adenoid cystic carcinoma $(1.55 \%, n=2)$. Regarding the incidence of oral SCC and its correlation with the anatomical sites, the left oral floor of the mucosa was the most affected (17 cases), followed by the lower lip (13 cases), right oral floor mucosa (11 cases), right mandibular alveolar mucosa (10 cases), right border of the tongue (eight cases), middle third of the tongue (eight cases), bilateral oral floor (six cases), left mandibular alveolar mucosa ( ix cases), left border of the tongue (five cases), base of the tongue (five cases), anterior third of the tongue (five cases), right maxillary mucosa (five cases), upper lip (four cases), soft palate (three cases), left jugal mucosa (two cases), right intermaxillary commissure (two cases), left intermaxillary commissure (two cases), left maxillary alveolar mucosa (two cases), right jugal mucosa (one case), right hard palate (one case), retromolar triangle (one case) and left tuberosity (one case). BCC was encountered at the lower lip (one case) and the upper lip (one case). Adenocarcinoma was found at the soft palate (two cases) and the right hard palate mucosa (two cases). Mucoepidermoid carcinoma was correlated with the mucosa of the right border of the tongue (one case) and the left jugal mucosa (two cases). Adenoid cystic carcinoma was the HP result in two cases, localized in the right maxillary mucosa and left oral floor mucosa.

The mentioned risk factors were associated with the differentiation grade of the oral tumors in Table 4.

Table 4 - Correlation between the risk factors and the tumor differentiation grade

\begin{tabular}{ccccc}
\hline Risk factors & G1 & G2 & G3 & G4 \\
\hline Tobacco & 12 & 15 & 20 & 20 \\
\hline Alcohol & 2 & 5 & 14 & 12 \\
\hline Tobacco + alcohol & 2 & 10 & 6 & 4 \\
\hline
\end{tabular}

The results indicate a strong relationship between them and the tumoral grading as follows: in case of tobacco, it was identified as a risk factor associated to G3 (poorly differentiated) tumors (20 cases), G4 (undifferentiated) tumors (20 cases), G2 (moderate differentiated) tumors (15 cases), and G1 (well differentiated) tumors (12 cases). Alcohol was a risk factor for 31 patients, and it was associated with G1 tumors (two cases), G2 tumors (five cases), G3 tumors (14 cases) and G4 tumors (12 cases). In case of the correlation of both risk factors, tobacco and alcohol were encountered in G3 tumors (seven cases), G4 tumors (six cases), G2 tumors (seven cases) and in G1 tumors (two cases). Taking into consideration these results, we can state the fact that the presence of the risk factors, alone or combined, can be related to the tumoral grading suggesting a higher incidence of the poorly differentiated and undifferentiated tumors. Nevertheless, these results can further suggest a poor prognosis in case of the existence of these risk factors (Table 4).

\section{ㅁ Discussions}

Oral cancer is a major public health problem that is continuously influenced by social factors [23, 24], oral SCC representing $90 \%$ of the oral malignant lesions. In our retrospective study, males were the majority $(65.9 \%)$ as also mentioned in the existing epidemiological studies $[25,26]$. Among the identified associated risk factors, tobacco was encountered in $52 \%$ of the cases, according to the results of other several studies [27]. The average age (including both genders) was 63.9 years, suggesting that the variable age should be considered a risk factor as well. According to Zini et al. [27], the lower lip cancer was the most prevalent oral tumor in their study, our results are according to these findings. An explanation could be that the lower lip is constantly exposed to intensive sun exposure and the is the most common location of SCC [28].

Anatomical sites of the oral mucosa with the higher incidence of malignant lesions were the floor of the mouth and the tongue, confirmed also by Chen et al. [29] in 
their study. SCC was the main HP subtype encountered in the present study, correlation that was proved in more conducted studies [30].

An explanation for the T3 and T4 staging and the delayed diagnosis, taking into consideration that in our study the incidence was $41 \%$, respectively $27 \%$ of the total of 129 patients, could be different socio-economic factors. The importance of the tumor staging is its association to the survival chances, statistics revealing a poor prognosis in case of the advanced late stages. A study performed by Razak et al. [31] showed that the group of oral cancer patients diagnosed with T4 tumors were not alive after five years. The management of oral cancer is a complex process, with functional and aesthetic consequences, influencing the mastication process, breathing, speech, taste, and jaw movement. The HP subtypes must be treated differently as the prognosis varies and the etiology and anatomical site is different.

The most common HP subtype of oral cancer is the oral SCC, counting over $90 \%$ of the cases [32], followed by other HP entities such as BCC, verrucous carcinoma, adenocarcinoma, adenoid cystic carcinoma, mucoepidermoid, lymphoma, sarcoma, and melanoma. The HP subtype can influence the survival rate, the involvement of loco-regional lymph nodes, the treatment, and the future prognosis. According to the literature, the BCC has a high percentage of infiltration and can occur due to an excessive sun exposure [33]. Lymphoma was classified as being the third most common, and together with sarcoma affected more frequently $<20$ years age group [34]. Studied reported a low incidence of melanoma in the oral cavity, being surpassed by the incidence of various metastases in the oral tissue [35]. Oral cancer lesions can develop in different locations of the oral cavity, being also influences by the direct exposure to multiple risk factors. Studies revealed the fact that in the oral cavity the incidence of the malignant lesions is different, the tongue and the jugal mucosa with a higher prevalence, followed by lips, floor of the mouth, gums, retromolar area, hard and soft palate [36].

The incidence rate, the mortality and survival rate are the characteristics that reveal the impact of oral cancer upon the population. Until now, oral cavity cancer is associated with one of the lowest survival rates although advancements have been made in the diagnosis and treatment $[37,38]$. Studies reveal that one of the main problems concerning oral cancer is the fact that approximately $50 \%$ of the lesions are diagnosed in advanced stages, despite the examination accessibility of the oral mucosa [39]. In numerous cases, regardless the location, the stage, or the therapeutic approaches $50 \%$ of the patients will have a relapse [40]. Research points out the existing cell interactions encountered in the tumor microenvironment as having a key role in the tumor progression [41]. The primary care provider can influence positively the early oral cancer diagnosis, fact that was stated by Alho et al. [42] in their study, where patients with initial symptomatology of tongue cancer were overlooked by the primary health care provider, had an increased death risk with three years compared to those patients that were early diagnosed.
The education available for the public should include the variety of symptoms related to oral cancer, the existing risk factors, and the importance of an early diagnosis. Among the risk factors, the genetic alterations and environmental factors play a key role, also the association of the HPV and Epstein-Barr virus (EBV), recurrent candidiasis infections in the incidence of oral cancer gained attention during the past years [43]. The management of oral cancer is a challenge, as the mortality rate is high, the late diagnosis and the mutilating treatments have an important influence upon the patient's quality of life.

\section{ㅁ Conclusions}

The incidence of oral cancer is increasing and among the major prognosis factors are the tumor staging, histological differentiation, and the loco-regional metastasis. Unfortunately, the reports reveal the fact that most of the cases are diagnosed in an advanced stage with minimal chances of survival. The importance of the preventive measures, the education and the regular check-ups can have a positive impact upon the early diagnosis.

\section{Conflict of interests}

The authors declare that they have no conflict of interests.

\section{References}

[1] McCullough MJ, Prasad G, Farah CS. Oral mucosal malignancy and potentially malignant lesions: an update on the epidemiology, risk factors, diagnosis and management. Aust Dent J, 2010, 55(Supp 1):61-65. https://doi.org/10.1111/j.1834-7819.2010. 01200.x PMID: 20553246

[2] Brocklehurst P, Kujan O, O'Malley LA, Ogden G, Shepherd S, Glenny AM. Screening programmes for the early detection and prevention of oral cancer. Cochrane Database Syst Rev, 2013, 2013(11):CD004150. https://doi.org/10.1002/14651858. CD004150.pub4 PMID: 24254989 PMCID: PMC8078625

[3] Ferlay J, Shin HR, Bray F, Forman D, Mathers C, Parkin DM. Estimates of worldwide burden of cancer in 2008: GLOBOCAN 2008. Int J Cancer, 2010, 127(12):2893-2917. https://doi.org/ 10.1002/ijc.25516 PMID: 21351269

[4] Sarode G, Maniyar N, Sarode SC, Jafer M, Patil S, Awan KH. Epidemiologic aspects of oral cancer. Dis Mon, 2020, 66(12): 100988. https://doi.org/10.1016/j.disamonth.2020.100988 PMID: 32605720

[5] Krishna Rao SV, Mejia G, Roberts-Thomson K, Logan R. Epidemiology of oral cancer in Asia in the past decade - an update (2000-2012). Asian Pac J Cancer Prev, 2013, 14(10): 5567-5577. https://doi.org/10.7314/apjcp.2013.14.10.5567 PMID: 24289546

[6] Conway DI, Purkayastha M, Chestnutt IG. The changing epidemiology of oral cancer: definitions, trends, and risk factors. Br Dent J, 2018, 225(9):867-873. https://doi.org/10. 1038/sj.bdj.2018.922 PMID: 30412558

[7] Chi AC, Day TA, Neville BW. Oral cavity and oropharyngeal squamous cell carcinoma - an update. CA Cancer J Clin, 2015, 65(5):401-421. https://doi.org/10.3322/caac.21293 PMID: 26215712

[8] Gandini S, Botteri E, lodice S, Boniol M, Lowenfels AB, Maisonneuve $\mathrm{P}$, Boyle $\mathrm{P}$. Tobacco smoking and cancer: a meta-analysis. Int J Cancer, 2008, 122(1):155-164. https:// doi.org/10.1002/ijc.23033 PMID: 17893872

[9] Rosenquist K. Risk factors in oral and oropharyngeal squamous cell carcinoma: a population-based case-control study in southern Sweden. Swed Dent J Suppl, 2005, (179):1-66. PMID: 16335030

[10] Bagnardi V, Rota M, Botteri E, Tramacere I, Islami F, Fedirko V, Scotti L, Jenab M, Turati F, Pasquali E, Pelucchi C, Galeone C, 
Bellocco R, Negri E, Corrao G, Boffetta P, La Vecchia C. Alcohol consumption and site-specific cancer risk: a comprehensive dose-response meta-analysis. $\mathrm{Br} \mathrm{J}$ Cancer, 2015, 112(3):580-593. https://doi.org/10.1038/bjc.2014.579 PMID: 25422909 PMCID: PMC4453639

[11] Chang JS, Straif K, Guha N. The role of alcohol dehydrogenase genes in head and neck cancers: a systematic review and meta-analysis of $A D H 1 B$ and $A D H 1 C$. Mutagenesis, 2012, 27(3):275-286. https://doi.org/10.1093/mutage/ger073 PMID 22042713

[12] Tsai ST, Wong TY, Ou CY, Fang SY, Chen KC, Hsiao JR, Huang CC, Lee WT, Lo HI, Huang JS, Wu JL, Yen CJ, Hsueh WT, Wu YH, Yang MW, Lin FC, Chang JY, Chang KY, Wu SY, Liao HC, Lin CL, Wang YH, Weng YL, Yang HC, Chang JS. The interplay between alcohol consumption, oral hygiene, $A L D H 2$ and $A D H 1 B$ in the risk of head and neck cancer. Int J Cancer, 2014, 135(10):2424-2436. https://doi.org/ 10.1002/ijc.28885 PMID: 24719202

[13] Mirghani H, Amen F, Moreau F, Lacau St Guily J. Do highrisk human papillomaviruses cause oral cavity squamous cel carcinoma? Oral Oncol, 2015, 51(3):229-236. https://doi.org/ 10.1016/j.oraloncology.2014.11.011 PMID: 25488179

[14] Wang L, Ganly I. The oral microbiome and oral cancer. Clin Lab Med, 2014, 34(4):711-719. https://doi.org/10.1016/j.cll. 2014.08.004 PMID: 25439271

[15] Hooper SJ, Wilson MJ, Crean SJ. Exploring the link between microorganisms and oral cancer: a systematic review of the literature. Head Neck, 2009, 31(9):1228-1239. https://doi.org/ 10.1002/hed.21140 PMID: 19475550

[16] Grulich AE, van Leeuwen MT, Falster MO, Vajdic CM. Incidence of cancers in people with HIVIAIDS compared with immunosuppressed transplant recipients: a meta-analysis. Lancet, 2007, 370(9581):59-67. https://doi.org/10.1016/S0140-6736 (07)61050-2 PMID: 17617273

[17] Collett D, Mumford L, Banner NR, Neuberger J, Watson C. Comparison of the incidence of malignancy in recipients of different types of organ: a UK Registry audit. Am J Transplant, 2010, 10(8):1889-1896. https://doi.org/10.1111/j.1600-6143. 2010.03181.x PMID: 20659094

[18] Edefonti V, Hashibe M, Ambrogi F, Parpinel M, Bravi F, Talamini R, Levi F, Yu G, Morgenstern H, Kelsey K, McClean M, Schantz S, Zhang Z, Chuang S, Boffetta P, La Vecchia C, Decarli A. Nutrient-based dietary patterns and the risk of head and neck cancer: a pooled analysis in the International Head and Neck Cancer Epidemiology Consortium. Ann Oncol, 2012, 23(7):1869-1880. https://doi.org/10.1093/annonc/mdr548 PMID: 22123733 PMCID: PMC3387823

[19] Bravi F, Bosetti C, Filomeno M, Levi F, Garavello W, Galimberti S, Negri E, La Vecchia C. Foods, nutrients and the risk of oral and pharyngeal cancer. Br J Cancer, 2013, 109(11):2904-2910. https://doi.org/10.1038/bjc.2013.667 PMID: 24149181 PMCID: PMC3844916

[20] Alter BP, Giri N, Savage SA, Quint WGV, de Koning MNC, Schiffman M. Squamous cell carcinomas in patients with Fanconi anemia and dyskeratosis congenita: a search for human papillomavirus. Int J Cancer, 2013, 133(6):1513-1515. https://doi.org/10.1002/ijc.28157 PMID: 23558727 PMCID: PMC3707947

[21] Lin WC, Lin YP, Wang YC, Chang TK, Chiang LC. Assessing and mapping spatial associations among oral cancer mortality rates, concentrations of heavy metals in soil, and land use types based on multiple scale data. Int J Environ Res Public Health, 2014, 11(2):2148-2168. https://doi.org/10.3390/ijerp h110202148 PMID: 24566045 PMCID: PMC3945590

[22] Riechelmann $\mathrm{H}$. [Occupational exposure and cancer of the oral cavity and pharynx]. Laryngorhinootologie, 2002, 81(8): 573-579. https://doi.org/10.1055/s-2002-33365 PMID: 12189574

[23] Madani AH, Dikshit M, Bhaduri D, Jahromi AS, Aghamolaei T. Relationship between selected socio-demographic factors and cancer of oral cavity - a case control study. Cancer Inform, 2010, 9:163-168. https://doi.org/10.4137/cin.s4774 PMID: 20838608 PMCID: PMC2935817

[24] Agarwal AK, Sethi A, Sareen D, Dhingra S. Treatment delay in oral and oropharyngeal cancer in our population: the role of socio-economic factors and health-seeking behaviour. Indian J Otolaryngol Head Neck Surg, 2011, 63(2):145-150. https:// doi.org/10.1007/s12070-011-0134-9 PMID: 22468251 PMCID: PMC3102173

[25] Mulligan R. The three phases of Eve: exploring the common and unique findings in oral and systemic health of differently aging women. Compend Contin Educ Dent, 2002, 23(10 Suppl): 32-40. PMID: 12790015

[26] Sarachev EL, Ananostev NH. Tendencies in the oral cavity cancer morbidity in three regions of South Bulgaria for a period of 15 years (1985-1999). Folia Med (Plovdiv), 2001, 43(1-2): 150-154. PMID: 15354492

[27] Wünsch-Filho $\mathrm{V}$. The epidemiology of oral and pharynx cancer in Brazil. Oral Oncol, 2002, 38(8):737-746. https://doi.org/ 10.1016/s1368-8375(02)00066-0 PMID: 12570051

[28] Abreu MAMM, Silva OMP, Neto Pimentel DR, Hirata CHW, Weckx LLM, Alchorne MMA, Michalany NS. Actinic cheilitis adjacent to squamous carcinoma of the lips as an indicator of prognosis. Braz J Otorhinolaryngol, 2006, 72(6):767771. https://doi.org/10.1016/s1808-8694(15)31043-0 PMID: 17308829

[29] Chen YK, Huang HC, Lin LM, Lin CC. Primary oral squamous cell carcinoma: an analysis of 703 cases in southern Taiwan. Oral Oncol, 1999, 35(2):173-179. https://doi.org/10.1016/s1 368-8375(98)00101-8 PMID: 10435152

[30] Ribeiro ACP, Silva ARS, Simonato LE, Salzedas LMP, Sundefeld MLMM, Soubhia AMP. Clinical and histopathological analysis of oral squamous cell carcinoma in young people: a descriptive study in Brazilians. $\mathrm{Br} \mathrm{J}$ Oral Maxillofac Surg, 2009, 47(2):95-98. https://doi.org/10.1016/j.bjoms.2008.05. 004 PMID: 18586366

[31] Razak AA, Saddki N, Naing NN, Abdullah N. Oral cancer survival among Malay patients in Hospital Universiti Sains Malaysia, Kelantan. Asian Pac J Cancer Prev, 2010, 11(1): 187-191. PMID: 20593955

[32] Bsoul SA, Huber MA, Terezhalmy GT. Squamous cell carcinoma of the oral tissues: a comprehensive review for oral healthcare providers. J Contemp Dent Pract, 2005, 6(4):1-19. PMID: 16299602

[33] Epstein JB, Epstein JD, Le ND, Gorsky M. Characteristics of oral and paraoral malignant lymphoma: a population-based review of 361 cases. Oral Surg Oral Med Oral Pathol Oral Radiol Endod, 2001, 92(5):519-525. https://doi.org/10.1067/ moe.2001.116062 PMID: 11709688

[34] Bleyer A. Young adult oncology: the patients and their survival challenges. CA Cancer J Clin, 2007, 57(4):242-255. https:// doi.org/10.3322/canjclin.57.4.242 PMID: 17626120

[35] Jemal A, Siegel R, Ward E, Hao Y, Xu J, Murray T, Thun MJ. Cancer statistics, 2008. CA Cancer J Clin, 2008, 58(2):7196. https://doi.org/10.3322/CA.2007.0010 PMID: 18287387

[36] Zini A, Czerninski R, Sgan-Cohen HD. Oral cancer over four decades: epidemiology, trends, histology, and survival by anatomical sites. J Oral Pathol Med, 2010, 39(4):299-305. https://doi.org/10.1111/j.1600-0714.2009.00845.x PMID: 20040019

[37] Centelles PV, Seoane-Romero JM, Gómez I, Diz-Dios P, de Melo SN, Seoane J. Chapter 9: Timing of oral cancer diagnosis: implications for prognosis and survival. In: Ogbureke KUE (ed). Oral cancer. InTech Open, London, UK, 2012, 173-188. https://doi.org/10.5772/30591

[38] Güneri P, Epstein JB. Late stage diagnosis of oral cancer: components and possible solutions. Oral Oncol, 2014, 50(12): 1131-1136. https://doi.org/10.1016/j.oraloncology.2014.09.005 PMID: 25255960

[39] McGurk M, Chan C, Jones J, O'Regan E, Sherriff M. Delay in diagnosis and its effect on outcome in head and neck cancer. Br J Oral Maxillofac Surg, 2005, 43(4):281-284. https:// doi.org/10.1016/j.bjoms.2004.01.016 PMID: 15993279

[40] Li YY, Zhou CX, Gao Y. Moesin regulates the motility of oral cancer cells via MT1-MMP and E-cadherin/p120-catenin adhesion complex. Oral Oncol, 2015, 51(10):935-943. https://doi.org/10.1016/j.oraloncology.2015.07.003 PMID: 26194050

[41] TIsty TD, Coussens LM. Tumor stroma and regulation of cancer development. Annu Rev Pathol, 2006, 1:119-150. https://doi.org/10.1146/annurev.pathol.1.110304.100224 PMID: 18039110 
[42] Alho OP, Teppo H, Mäntyselkä P, Kantola S. Head and neck cancer in primary care: presenting symptoms and the effect of delayed diagnosis of cancer cases. CMAJ, 2006, 174(6):779-784. https://doi.org/10.1503/cmaj.050623 PMID: 16534084 PMCID: PMC1402394
[43] Chang ET, Adami HO. The enigmatic epidemiology of nasopharyngeal carcinoma. Cancer Epidemiol Biomarkers Prev, 2006, 15(10):1765-1777. https://doi.org/10.1158/1055 -9965.EPI-06-0353 PMID: 17035381

\section{Corresponding authors}

Mircea Riviş, Senior Lecturer, MD, PhD, Department of Anesthesiology and Oral Surgery, Multidisciplinary Center for Research, Evaluation, Diagnosis and Therapies in Oral Medicine, Faculty of Dental Medicine, Victor Babeş University of Medicine and Pharmacy, 2 Eftimie Murgu Square, 300041 Timişoara, Romania; Phone +40722-287 582, e-mail: rivis.mircea@umft.ro

Ciprian loan Roi, Associate Professor, MD, DMD, PhD, Department of Anesthesiology and Oral Surgery, Multidisciplinary Center for Research, Evaluation, Diagnosis and Therapies in Oral Medicine, Faculty of Dental Medicine, Victor Babeş University of Medicine and Pharmacy, 2 Eftimie Murgu Square, 300041 Timişoara, Romania; Phone +40748-245 993, e-mail: ciprian.roi@umft.ro

Received: January 9, 2021

Accepted: June 10, 2021 